\title{
PENGEMBANGAN POTENSI PARIWISATA SPIRITUAL BERBASIS MASYARAKAT LOKAL DI BALI
}

\author{
Sukadi, Sutama, Sanjaya \\ Universitas Pendidikan Ganesha
}

\begin{abstract}
Abstrak
Bali memiliki daya tarik wisata yang beragam. Wisata spiritual belum banyak dikembangkan oleh masyarakat lokal Bali. Tujuan penelitian tahun pertama ini adalah mengidentifikasi potensi pariwisata spiritual di Bali dan merumuskan strategi pengembangan serta pemasaran pariwisata spiritual di Bali. Penelitian ini dilakukan dengan pendekatan etnografi di tiga Kabuapten di Bali. Hasil penelitian ini menunjukkan bahwa Pura Lempuyang Luhur, Pura Penegil Dharma, Pura Negara Gambur Anglayang, Pura Ponjok Batu, Pura Pulaki, dan Pura Perancak dengan segala aktivitas spiritualnya sangat cocok dikembangkan sebagai objek wisata spiritual di Bali. Ini karena seluruh pura dapat memberikan pengalaman nilai-nilai historis, sosial budaya, dan nilai-nilai spiritual kepada wisatawan yang datang. Strategi pengembangan dan pemasaran yang masih harus dilakukan antara lain adalah pemberdayaan masyarakat lokal pengempon pura, koordinasi dengan pemkab dan pihak-pihak terkait, penataan lingkungan pura yang lebih baik, penyediaan sarana pendukung yang lebih baik, kegiatan inventarisasi dan dokumentasi, sosialisasi melalui media TIK, sosialisasi melalui kerja sama dengan asosiasi perhotelan dan jasa wisata lainnya, sosialisasi melalui desa pakraman, sekolah dan perguruan tinggi, dunia kerja dan industri, masyarakat transmigran Bali, dan masyarakat Hindu Nusantara.
\end{abstract}

Kata-kata kunci: pariwisata spiritual, masyarakat lokal

\begin{abstract}
Bali has a variety of tourist attraction. Spiritual tourism object has not been developed by local community in Bali. Accordingly to that issue, this first year research purpose are to indentify the existing potential of spiritual tourism in Bali and to formulate the development and marketing strategy of spiritual tourism in Bali. This research was conducted by an ethnographic approach in three districts in Bali. The result of this research indicate that Lempuyang Luhur temple, Penegil Dharma temple, Negara Gambur Anglayang temple, Ponjok Batu temple, Pulaki temple, and Perancak temple with all the spiritual activities are very suitable to be developed as spiritual tourism object in Bali. This is because those entire temples can provide experience of historical values, socio-cultural, and spiritual values to tourist who come to visit those temples. Development and marketing strategy that remains to be done is to empower the local community of pengempon pura; coordination with the district goverment and related staff; structuring the temple compound; providing better facilities for support; doing inventory and documentation; dissemination through ICT media; socialization through cooperation with the hotel association and other travel service; and socialization with pakramans, schools and universities, work and industry organization, the transmigrants of Balinese, and with National Hindu communities.
\end{abstract}

Keywords : spiritual tourism, local community.

\section{A. PENDAhUluan}

Penelitian MP3El Undiksha oleh Wesnawa dkk. (2011) menyatakan bahwa pengembangan pariwisata Bali dilakukan dengan memanfaatkan tiga jenis daya tarik wisata yakni daya tarik wisata alam, daya tarik wisata budaya, dan daya tarik wisata buatan/minat khusus. Tiga daya tarik wisata di atas, salah satunya adalah daya tarik wisata spiritual. Sampai saat ini potensi eksisting wisata spiritual yang ada belum dikembangkan secara optimal. Bersama 
dengan hal tersebut, kunjungan wisatawan ke Bali pada tahun 2010 meningkat sebanyak 1.172 .978 orang atau 20,39 persen. Memperhatikan data kunjungan pada tahun 2010, maka pada tahun 2011 Pemprov Bali memasang target kunjungan wisatawan nusantara berkisar antara 4,7-5 juta orang dan target kunjungan wisatawan mancanegara berkisar antara 2,6-2,7 juta orang (http://infopariwisata.wordpres.combali/). Dari jumlah kunjungan wisata tersebut telah banyak wisatawan yang melakukan wisata spiritual.

Sebagai tindak lanjut dari penelitian di atas, dilakukan penelitian tentang potensi dan eksisting pariwisata spiritual di Bali. Alasan pariwisata spiritual adalah bahwa pariwisata spiritual sesungguhnya sangat prospektif dan cocok dikembangkan di Bali karena daya dukung alam dan masyarakatnya yang religius. Selain itu, pariwisata spiritual belum banyak ada di wilayah lain di Indonesia. Pariwisata spiritual dapat menata tata kehidupan sosial budaya masyarakat Bali dengan berbagai keunikan adat-istiadat dan budaya. Hampir di setiap desa pakraman memiliki keunikan, baik adat-istiadat, budaya maupun kehidupan sosial yang didasarkan pada awig-awig. Selain itu, kawasan suci dengan lingkungan alamnya berupa perbukitan, pegunungan, pantai yang indah harus selalu dipelihara dan dibina. Mengembangkan pariwisata spiritual tidak selalu berpikir membangun hotel atau vila sebanyak-banyaknya, tetapi tetap pada pemberdayaan nilai sosial budaya masyarakat yang ada.

Bali merupakan satu-satunya daerah tujuan wisata yang memiliki pura terbanyak di dunia. Pura-pura yang ada, terutama Pura Sad Kahyangan atau Dang Kahyangan, sesungguhnya merupakan sebuah kisah perjalanan yang ditempuh oleh orang intelek dan suci di masa lalu dalam melakukan penyebaran agama, seperti Rsi Markandeya, Empu Kuturan, Dang Hyang Dwijendra atau Dang Hyang Nirartha, dan Mpu Bharadah. Perjalanan para Rsi tersebut sekaligus dapat dikategorikan sebagai wisata spiritual.

$\begin{array}{ccc}\text { Pura-pura } & \text { tersebut } & \text { perlu } \\ \text { diidentifikasi } & \text { potensinya } & \text { untuk } \\ \text { dikembangkan } & \text { dan dipasarkan } & \text { menjadi }\end{array}$ objek wisata spiritual di Bali berbasis masyarakat lokal. Untuk tujuan itulah penelitian ini dilakukan. Secara rinci tujuan khusus dari penelitian tahun pertama ini adalah: 1) mengidentifikasi potensi dan eksisting pariwisata spiritual di Bali dan 2) menghasilkan strategi pengembangan dan pemasaran pariwisata spiritual di Bali berbasis kearifan lokal masyarakat.

\section{B. METODE PENELITIAN}

Penelitian ini merupakan penelitian tahun pertama dari rencana dua tahun penelitian. Rancangan penelitian yang digunakan adalah studi etnografi. Penelitian dilakukan pada enam Pura Sad Kahyangan dan Dang Kahyangan di tiga Kabupaten, yaitu: Karangasem, Buleleng, dan Jembrana. Subjek penelitian yang dilibatkan meliputi: tokoh masyarakat, prajuru desa pakraman dan desa dinas, staff pada Dinas Kebudayaan dan Pariwisata di Kabupaten, budayawan, rohaniawan, serta subjek dokumen. Subjek dipilih secara purpossive dan dengan teknik snowball dimulai dengan menetapkan informan kunci dan selanjutnya dipilih sesuai dengan pilihan subjek. Data yang dikumpulkan dalam penelitian ini adalah berfokus pada identifikasi potensi dan eksisting pariwisata spiritual di Bali dan strategi pengembangan dan pemasaran pariwisata spiritual di Bali berbasis kearifan lokal masyarakat. Data dikumpulkan dengan metode wawancara mendalam, observasi, kajian dokumen, dan diskusi kelopok fokus. Data yang diperoleh lalu dianalisis secara kualitatif melalui siklus interaktif, yang meliputi: pengumpulan data, reduksi data, display data, dan penarikan kesimpulan atau verifikasi (Milles dan Huberman, 1992). 


\section{HASIL PENELITIAN DAN PEMBAHASAN}

Hasil penelitian ini dideskripsikan dan dijelaskan dalam dua tema pokok, yaitu Pura-pura Sad Kahyangan dan Dang Kahyangan yang memiliki potensi untuk dikembangkan menjadi objek wisata spiritual berbasis kearifan lokal masyarakat dan strategi pengembangan dan pemasaran objek wisata spiritual yang melibatkan partisipasi masyarakat lokal pengempon pura.

Pura pertama yang memiliki potensi untuk dikembangkan menjadi objek wisata spiritual adalah Pura Lempuyang luhur. Sebagai Pura Sad kahyangan Jagat, pura ini sangat cocok dikembangkan menjadi objek wisata spiritual di Bali. Ini dilakukan karena keberadaan Pura Lempuyang Luhur dengan segala aktivitas spiritualnya dapat memberikan pengalaman nilai historis, sosial budaya, dan spiritual yang tinggi kepada para wisatawan (Adnyana Ole, 2008a).

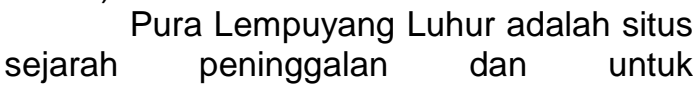
penghormatan serta pemuliaan kepada Mpu Genijaya di Bali. Keberadaan pura ini berkaitan dengan kedatangan Bhatara Tiga di Bali pada sekitar Tahun 191 M dari Gunung Semeru di Jawa Timur atas perintah Bhatara Pacupati. Di antara Bhatara Tiga itu Bhatara Gnijaya berparhyangan di gunung Lempuyang (bukit bisbis). Ida Bhatara Gnijaya diperintahkan untuk menjadi pemimpin umat di Bali dan mengajarkan agama Hindu serta nilai-nilai kehidupan kepada masyarakat Bali. Karena itu, sebagai wujud pemuliaan kepadanya beliau kemudian distanakan di Pura Lempuyang luhur dan dipuja sebagai Dewa Icwara. Dewa yang memberikan sinar suci kehidupan kepada umat manusia (Bali Post, 2006).

Pura ini sekarang terletak di puncak gunung bisbis, yaitu di desa Purwayu Kecamatan Abang Kabupaten Karangasem. Melakukan aktivitas spiritual di lingkungan pura ini juga dapat memberikan pengalaman proses pendakian spiritual yang membahagiakan. Dimulai dari menghaturkan sembah di Pura Penataran Agung Lempuyang sebagai pesanakan Pura Lempuyang Luhur yang paling bawah. Perjalanan lalu dilanjutkan menuju Pura Telaga Mas sebagai tempat pesucian Ida Bhatara. Di sini umat mendapat air suci untuk pembersihan diri secara lahir dan bathin. Perjalanan kemudian dilanjutkan dengan naik gunung ke Pura Telaga Wangsa dan Pura Lempuyang Madya sebagai tempat meditasi Ida Bhatara. Setelah itu perjalanan dapat dilanjutkan dengan pendakian ke Pura Puncak Bisbis dan Pura Pasar Agung. Sesuai dengan namanya Pura Pasar Agung adalah sebagai tempat aktivitas jual beli untuk memenuhi kebutuhan hidup sebelum melanjutkan perjalanan ke puncak pendakian paling tinggi di Pura Lempuyang Luhur. Di Pura terakhir dan utama ini kita melakukan meditasi menunggalkan pikiran kepada Tuhan Yang Maha Esa dalam manifestasi beliau sebagai Dewa Icwara. Proses pendakian spiritual dari Pura Penataran Agung hingga Pura Lempuyang Luhur inilah sesungguhnya manusia dapat belajar meniti kehidupan dari yang paling bawah hingga mencapai puncak tujuan hidup, yaitu mencapai kebahagian lahir dan bathin (Intra AS, 2011).

Pura kedua yang juga cocok dikembangkan menjadi objek wisata spiritual di Bali adalah Pura Penegil Dharma dengan pesanakannya yang berjumlah delapan sebagai simbol Padma Bhuwana. Kompleks Pura ini terletak di Desa Kubutambahan dan Desa Bulian Kecamatan Kubutambahan Kabupaten Buleleng. Melakukan wisata spiritual di seluruh kompleks pura ini dapat memberikan pengalaman nilai-nilai historis, sosial budaya, dan spiritual yang tinggi kepada para wisatawan (Ari Sri lestari, 2006).

Dikatakan memiliki nilai historis karena keberadaan kompleks pura ini tidak bisa dilepaskan dari kekuasaan Raja Ugracena dengan gelar Sri Kesari Warmadewa di Bali dengan penasihat 
spiritualnya adalah Rsi Mankandeya. Raja Ugracena dan Rsi Markandeya tidaklah hanya pemimpin masyarakat, tetapi juga memiliki kemampuan spiritual kepanditaan yang tinggi, sehingga istananya tidak saja menjadi pusat pemerintahan tetapi juga menjadi pusat pendidikan agama dan sebagai petirtan (tempat air suci kehidupan) dengan adanya 118 sumber mata air (Gobyah, 2006).

Melakukan aktivitas spiritual di lingkungan pura ini juga dapat memberikan pengalaman hidup bertoleransi dalam kehidupan masyarakat multikultur di Indonesia. Ini terjadi karena dari peninggalan sejarahnya dapat diketahui bahwa pada masa pemerintahan Raja Ugracena kerajaan Kawista telah menjadi pusat perdagangan dan pusat pendidikan agama yang didatangi orang dari berbagai suku dan bangsa yang berbeda dengan keyakinan yang berbeda juga. Yang unik, keberagaman itu justru disungsung di pura ini dengan adanya pelingih-pelinggih pura sebagai stana Ratu Gede Sundawan (unsur Sunda), Ratu Gede Melayu (unsur Melayu), Ratu Mas Subandar (unsur Cina), dan Ratu Dalem Mekah (unsur Islam), di samping ada juga pelinggih stana Dewa Ciwa (unsur Hindu). Pada pokoknya Pura Penegil Dharma dengan pesanakannya adalah situs sejarah peninggalan dan penghormatan kepada keluarga raja Sri Kesari Warmadewa dan raja Sri Singa Murti di Bali (Paramartha, $\mathrm{tt})$.

Pura Negara Gambur Anglayang sebagai objek ketiga, seperti Pura Penegil Dharma, juga sangat cocok dikembangkan menjadi objek wisata spiritual di Bali. Ini dilakukan karena keberadaan Pura ini dengan segala aktivitas spiritualnya dapat memberikan pengalaman nilai historis, sosial budaya, dan spiritual yang tinggi kepada para wisatawan. Melakukan aktivitas spiritual di lingkungan pura ini juga dapat memberikan pengalaman hidup bertoleransi dalam kehidupan masyarakat multikultur di Indonesia. Pura ini adalah situs sejarah peninggalan dan penghormatan kepada keluarga raja Sri Singa Murti di Bali (Adnyana Ole, 2011, 2008b; Darmawan M., 2008).

Pura Ponjok Batu sebagai objek keempat juga sangat cocok dikembangkan menjadi objek wisata spiritual di Bali. Ini dilakukan karena keberadaan Pura ini dengan segala aktivitas spiritualnya dapat memberikan pengalaman nilai historis, sosial budaya, dan spiritual yang tinggi kepada para wisatawan. Melakukan aktivitas spiritual di lingkungan pura ini juga dapat memberikan pengalaman hidup bertoleransi dan memberikan sinar kehidupan suci kepada masyarakat. Pura ini adalah situs sejarah peninggalan dan penghormatan kepada Dang Hyang Nirartha dalam melakukan perjalanan tirtha yatra dan memberikan ajaran agama Hindu di Bali (Adnyana Ole, 2006b; Arie Sri lestari, tt; Gobyah, 2011).

Pura Pulaki dengan pesanakannya (Pura Melanting, Pura Kertha Kawat, Pura Pemuteran, dan Pura Pabean) sebagai objek yang kelima sangat cocok menjadi objek wisata spiritual di Bali. Ini terjadi karena keberadaan Pura ini dengan segala aktivitas spiritualnya dapat memberikan pengalaman nilai historis, sosial budaya, dan spiritual yang tinggi kepada para wisatawan. Melakukan aktivitas spiritual di lingkungan pura ini juga dapat memberikan pengalaman hidup bertoleransi dan memberikan sinar kehidupan suci kepada masyarakat dalam mengembangkan aktivitas usaha secara fungsional di masyarakat. Pura ini adalah situs sejarah peninggalan dan penghormatan kepada Dang Hyang Nirartha dan keluarganya (Ida Bhatari Dalem Ketut Pulaki, Ida Bhatari Dewa Ayu Melanting, dan Ida Bhatara Mentang Yuda atau Ida Bhatara Hakim Agung) dalam melakukan perjalanan tirtha yatra dan mengajarkan agama Hindu dan ajaran nilai-nilai kehidupan di Bali (Adnyana Ole, 2006a; Pemkab Buleleng, 2012; PHDI, 2000).

Pura Perancak sebagai objek pura keenam juga sangat cocok dikembangkan 
menjadi objek wisata spiritual di Bali. Ini dilakukan karena keberadaan Pura ini dengan segala aktivitas spiritualnya dapat memberikan pengalaman nilai historis, sosial budaya, dan spiritual yang tinggi kepada para wisatawan. Melakukan aktivitas spiritual di lingkungan pura ini juga dapat memberikan pengalaman hidup bertoleransi dan memberikan sinar kehidupan suci kepada masyarakat. Pura ini adalah situs sejarah peninggalan dan penghormatan kepada Dang Hyang Nirartha dalam melakukan perjalanan tirtha yatra dan memberikan ajaran agama Hindu di Bali (Asram Bunda RAM, 2010; Fajar Arcana, tt; Yudi, 2012).

Untuk menjadikan Pura-pura Sad Kahyangan Jagat dan Pura-pura Dang Kahyangan di Bali sebagai objek wisata spiritual perlu dikembangkan strategi pengembangan dan pemasaran berdasarkan hasil analisis SWOT terhadap keberadaannya. Strategi pengembangan dan pemasaran yang masih harus dilakukan antara lain adalah pemberdayaan masyarakat lokal pengempon pura agar mampu mengelola usaha wisata spiritual. Masyarakat pengempon pura perlu berkoordinasi dengan pemkab dan pihakpihak terkait dalam memberikan dukungan fasilitas dan sarana yang memadai untuk penunjang kegiatan pariwisata spiritual di lingkungan pura masing-masing. Masyarakat juga masih perlu melakukan penataan lingkungan pura yang lebih baik agar kondisinya tetap bersih, asri, hijau, sehat, lestari, nyaman, dan aman. Karena itu, diperlukan penyediaan sarana pendukung yang lebih baik seperti penyediaan sarana parkir yang memadai, sarana listrik, air bersih, dan tempat untuk membersihkan diri secara lahir dan bathin, serta peralatan kebersihan lingkungan yang memadai.

Jika penataan lingkungan spiritual pura telah memadai, maka kegiatan sosialisasi untuk pemasaran objek wisata spiritual perlu terus dikembangkan. Kegiatan yang utama adalah aktivitas inventarisasi dan dokumentasi semua potensi yang dimiliki pura dengan segala aktivitas spiritualnya, terutama yang menyangkut nilai-nilai historis pura, aktualisasi nilai-nilai kesadaran sosial dan budaya yang melingkupi, serta nilai-nilai spiritual yang dikandungnya. Jika ini sudah dilakukan, usaha berikutnya adalah sosialisasi potensi pura dengan aktivitas spiritualnya kepada masyarakat melalui media TIK, sosialisasi melalui kerja sama dengan asosiasi perhotelan dan jasa wisata lainnya, sosialisasi melalui desa pakraman, sekolah dan perguruan tinggi, dunia kerja dan industri, masyarakat transmigran Bali, dan masyarakat Hindu Nusantara.

\section{PEMBAHASAN}

Penelitian ini menemukan bahwa Pura-pura Sad Kahyangan dan Dang Kahyangan di Bali yang menjadi objek dalam penelitian ini dengan segala aktivitas spiritualnya sangat cocok dikembangkan menjadi objek wisata spiritual di Bali. Ini dilakukan karena seluruh pura dapat memberikan pengalaman nilai-nilai historis, sosial budaya, dan nilai-nilai spiritual kepada wisatawan yang datang. Temuan ini cocok dengan pandangan yang menyatakan bahwa wisata spiritual merupakan perjalanan yang memperkaya batin individu secara personal meski tidak terkait dengan anjuran dalam ajaran agama yang dipeluknya (Herdina, 2012). Jenis wisata ini dalam praktiknya sangat menghargai tradisi budaya lokal, mencintai alam dan lingkungan, serta sebagian besar turisnya berasal dari kalangan yang berpendidikan (Pitana, 2012). Objek wisata spiritual ini bukanlah mendiskusikan agama semata. Kecenderungannya justru orang lebih melirik berbicara spiritual. Mereka mencari peace and harmony. Menurut Pitana (2012) lebih lanjut para wisatawan dewasa ini telah melirik nilai-nilai historis, praktik sosial budaya masyarakat tradisional yang toleran dan ramah lingkungan, dan nilai-nilai spiritual yang penuh kedamaian sebagai objek wisatanya. 
Temuan kedua penelitian ini menunjukkan bahwa strategi pengembangan dan pemasaran wisata spiritual masih harus dilakukan oleh masyarakat lokal untuk meningkatkan minat wisatawan. Upaya-upaya yang harus dilakukan, antara lain: memberdayakan masyarakat lokal pengempon pura, berkoordinasi dengan pemkab dan pihakpihak terkait, menata lingkungan pura yang lebih baik, menyediakan sarana pendukung yang lebih baik, melakukan inventarisasi dan dokumentasi, sosialisasi dan promosi melalui media TIK, sosialisasi melalui kerja sama dengan asosiasi perhotelan dan jasa wisata lainnya, serta sosialisasi / promosi melalui desa pakraman, sekolah dan perguruan tinggi, dunia kerja dan industri, masyarakat transmigran Bali, dan masyarakat Hindu Nusantara. Temuan ini relevan dengan upaya-upaya yang dilakukan pemerintah dan masyarakat serta pihak-pihak terkait untuk menarik minat wisatawan datang ke daerah-daerah tujuan wisata tertentu (lihat Hidayatulloh, 2011; Yusmiarti, 2009; Santosa, 2002).

\section{PENUTUP}

Berdasarkan uraian di atas dapat disimpulkan bahwa Pura Lempuyang Luhur, Pura Penegil Dharma, Pura Negara Gambur Anglayang, Pura Ponjok Batu, Pura Pulaki, dan Pura Perancak dengan segala aktivitas spiritualnya sangat cocok dikembangkan sebagai objek wisata spiritual di Bali. Ini dilakukan karena seluruh pura dapat memberikan pengalaman nilai-nilai historis, sosial budaya, dan nilai-nilai spiritual kepada wisatawan yang datang. Strategi pengembangan dan pemasaran yang masih harus dilakukan antara lain adalah pemberdayaan masyarakat lokal pengempon pura, koordinasi dengan pemkab dan pihak-pihak terkait, penataan lingkungan pura yang lebih baik, penyediaan sarana pendukung yang lebih baik, kegiatan inventarisasi dan dokumentasi, sosialisasi melalui media TIK, sosialisasi melalui kerja sama dengan asosiasi perhotelan dan jasa wisata lainnya, sosialisasi melalui desa pakraman, sekolah dan perguruan tinggi, dunia kerja dan industri, masyarakat transmigran Bali, dan masyarakat Hindu Nusantara.

Ada beberapa rekomendasi yang dapat diajukan dari hasil penelitian ini untuk mengembangkan dan memasarkan Purapura Sad Kahyangan dan Dang Kahyangan sebagai objek wisata spiritual yang baik. Pertama, pemerintah kabupaten perlu lebih dapat memberdayakan masyarakat lokal desa pakraman pengempon pura. Kedua, masyarakat lokal desa pakraman harus melakukan inventarisasi dan dokumentasi potensi wisata spiritual yang dimiliki oleh lingkungan suci Pura Sad Kahyangan dan Pura Dang Kahyangan dengan segala aktivitas spiritual yang didukung oleh masyarakat. Ketiga, masyarakat lokal desa pakraman perlu menyiapkan dan mengembangkan fasilitas dan sarana pendukung usaha wisata spiritual. Keempat, masyarakat lokal desa pakraman perlu melakukan koordinasi dan kerja sama yang baik dengan asosiasi perhotelan dan asosiasi jasa wisata lainnya. Kelima, masyarakat lokal desa pakraman pengempon pura perlu melakukan koordinasi dan kerja sama yang baik dengan kelompok masyarakat desa pakraman, sekolah, perguruan tinggi, dan dunia kerja dalam memberikan informasi tentang keberadaan potensi objek wisata spiritual lingkungan suci pura. Keenam, masyarakat lokal desa pakraman perlu menyiapkan sumber daya manusia yang memadai untuk mampu mengelola usaha wisata spiritual. Ketujuh, perlu studi inventarisasi dan dokumentasi potensi wisata spiritual lingkungan suci Pura Sad Kahyangan dan Pura Dang Kahyangan. Kedelapan, perlu sosialisasi kekayaan budaya spiritual lingkungan suci pura melalui media teknologi informasi dan komunikasi (TIK). Kesembilan, perlu sosialisasi kekayaan budaya spiritual lingkungan suci pura melalui jalur keluarga, desa pakraman di Bali, sekolah dan 
perguruan tinggi, dunia kerja dan dunia industri, kelompok masyarakat Bali transmigran, dan kelompok masyarakat Hindu yang tersebar di seluruh nusantara. Kesepuluh, perlu sosialisasi melalui jalur kerja sama dengan asosiasi perhotelan dan asosiasi usaha jasa perjalanan wisata. Terakhir, perlu penyusunan buku-buku spiritual tentang keberadaan dan perkembangan aktivitas spiritual di lingkungan suci Pura-pura Sad Kahyangan dan Dang Kahyangan.

\section{DAFTAR RUJUKAN}

Adnyana Ole. 2011. Pura Negara Gambur Anglayang Spirit Multikultural. http://www.balipost.com/mediadetail.p hp? module $=$ detailberita\&kid $=21 \& i d=5$ 8168. Diunduh pada Hari Sabtu, 4 Agustus 2012.

http://departelahne.wordpress.com/20 08/10/09/pura-luhurlempuyang/\# more -24. Diunduh pada Hari Sabtu, 4 Agustus 2012.

2008b. Pura Gambur Anglayang. http://www.babadbali.com/ pura/plan/gambur-anglayang.htm.

Diunduh pada Hari Sabtu, 4 Agustus 2012. Suci Peninggalan Prasejarah. http://www.balipost.co.id/BaliPostceta k/2006/1/18/bd2.htm. Diunduh pada Hari Sabtu, 4 Agustus 2012.

2006b. Pura Ponjok Batu: Penyeimbang Bali Utara. http://kemoning.info/blogs/?p=864.

Diunduh pada Hari Sabtu, 4 Agustus 2012.

Arie sri lestari, 2006. Pura Penegil Dharma Berawal dari Kerajaan Kawista. http://www.balipost.co.id/balipostcetak /2006/7/12/bd2.htm. Diunduh pada Hari Sabtu, 4 Agustus 2012.

Tt. Pura Ponjok Batu. http://www.babadbali.com/pura/plan/p onjok-batu.htm. Diunduh pada Hari Sabtu, 4 Agustus 2012.

Asram Bunda RAM. 2010. Pura Perancak. http://asrambundaram.blogspot. com/2010/04/pura-perancak.html. Diunduh pada Hari Sabtu, 4 Agustus 2012.

Bali Post. 2006. Pura Lempuyang, "Stana" Dewa Iswara. http://www.balipost. co.id/balipostcetak/2006/2/15/bd2.htm Diunduh pada Hari Sabtu, 4 Agustus 2012.

Darmawan Mataram. 2008. Pura Negara Gambur Anglayang. http://balitv.tv/ btv2/index.php/ista-dewata/658-puranegara-gambur-anglayang. Diunduh pada Hari Sabtu, 4 Agustus 2012.

Dinas Kebudayaan Propinsi Bali. 1980/ 1981. Pura-Pura di Bali. Denpasar: Dinas Kebudayaan Propinsi Bali.

Fajar Arcana, P. Pura Perancak. http:// www.parisada.org/index.php?

option=com content\&task=view\&id $=5$ 3\&ltemid=99. Diunduh pada Hari Sabtu, 4 Agustus 2012.

Gobyah I K. 2011. Pura Ponjok Batu. http:// binginbanjah.wordpress.com/2011/02/ 21/pura-ponjok-batu/. Diunduh pada Hari Sabtu, 4 Agustus 2012 2006. Pura Penegil Dharma.

http://www.balipost.co.id/ balipostcetak/2006/7/12/bd1.htm. Diunduh pada Hari Sabtu, 4 Agustus 2012.

Herdina, L. 2012. Wisata Spiritual, Perjalanan Suci Peziarah Urban. http://wisata.kompasiana.com/jalanjalan/2012/10/15/wisata-spiritualperjalanan-suci-peziarah-urban/. Diunduh pada hari Sabtu, 17 Nopember 2012. 
idayatulloh, Y N. 2011. Strategi Pemasaran Objek Wisata Alam Talaga Remis di Taman Nasional Gunung Ciremai. http://repository.ipb.ac.id/handle/ 123456789/49867. Diunduh pada Hari Senin, 22 April 2013

Huberman, A.B dan Miles M.B. 1992. Analisis Data Kualitatif. (Terjemahan). Jakarta: UI Press.

Intra AS. 2011. Pura Lempuyang Luhur Puncak Bisbis. http://pendakian spiritual.blogspot.com/2011/09/puralempuyang-luhur-puncak-bisbis.html. Diunduh pada Hari Sabtu, 4 Agustus 2012.

Paramartha, N. tt. Jejak Pura Puseh Penegil Dharma, Pusat Pengembangan Agama dan Pemerintahan. http://www.babadbali.com/pura/plan/p enegil-darma. htm. Diunduh pada Hari Sabtu, 4 Agustus 2012.

Pemkab Buleleng. 2012. Pura Pulaki. http://bulelengkab.go.id/v1/index.php/ 2012-04-03-06-05-52/potensipariwisata/pariwisata-bulelengbarat/71-pura-pulaki. Diunduh pada Hari Sabtu, 4 Agustus 2012.

PHDI. 2000. Pura Pulaki: Tempat Moksah Sri Patni Keniten. http://www. parisada.org/index.php?option $=\mathrm{com} \mathrm{C}$ ontent\&task=view\&id=650\&ltemid=99. Diunduh pada Hari Sabtu, 4 Agustus 2012.

Pitana, G. 2012. Wisata Spiritual Potensial Dikembangkan. Kompas.Com. http://travel.kompas.com/read/2012/0 8/02/1923017/. Diunduh pada hari Sabtu, 17 Nopember 2009.

Santosa, S P. 2002. Pengembangan Pariwisata Indonesia. http://kolom. pacific.net.id/ind/setyanto_p._santosa/ artikel_setyanto_p._santosa/pengemb angan_pariwisata_indonesia.html. Diunduh pada Hari Senin, 22 April 2013.

Wesnawa, I Gede Astra, Sanjaya, D. B., Widiastini, $\mathrm{Ni}$ Made Ary.2011. Pengembangan Potensi Pariwisata Berkelanjutan bagi Peningkatan Kehidupan Sosial Ekonomi Masyarakat pada Koridor Bali sebagai Pintu Gerbang Pariwisata Nasional. Laporan Penelitian. Program MP3EI Undiksha Singaraja.

Yudi FX, G. 2012. Pura Perancak. http://deyudi.com/pura-perancak. Diunduh pada Hari Sabtu, 4 Agustus 2012.

Yusmiarti, A. 2009. Promotion Strategies of The Culture and Tourism Service of The Kulon Progo Regency to Increase The Visitours of Sermo Dam in The Kulon Progo Regency of Yogyakarta.http://publikasi.umy.ac.id/ index.php/komunikasi/article/view/95/ 2263. Diunduh pada Hari Senin, 22 April 2013. 